\title{
A Review, an Integration, and a Critique of Cross-Disciplinary Research on Performance Appraisals, Evaluations, and Feedback: 1990-2000
}

\author{
Deloris McGee Wanguri ${ }^{[a], *}$
}

\author{
${ }^{[a]}$ Professor. Department of Arts and Humanities, University of Houston \\ Downtown, Houston, Texas, USA. \\ *Corresponding author. \\ Received 7 April 2014; accepted 12 June 2014 \\ Published online 27 July 2014
}

\begin{abstract}
Performance related pay and the performance appraisal system continue to have a strong presence in corporate America. The presence of the performance appraisal system ranges from more traditional paper-and-pen systems to the emergence of eAppraisal, a web-based software designed by Halogen to facilitate the appraisal process. The current study investigates trends in this area. Ninety-eight empirical studies on performance appraisals, published between 1990 and 2000, in business, communication, and psychology journals, were reviewed and integrated. This review examined published empirical studies in four categories: performance appraisal systems and practices, rating instruments, raters, and ratees. Results of this synthesis revealed the following: (a) Effective performance appraisal systems feature opportunities for employee "voice"; (b) PRP systems are being implemented with increasing frequency internationally; (c) BOS are superior to BARS and GRS in terms of goal specificity; (d) all types of appraisal systems are subject to rating distortion; (e) multirater, SAM, and peer review feedback programs should be used most frequently for developmental purposes and performance improvement; (f) perceived accuracy of performance feedback is an important component of the evaluation process; (g) acceptance of subordinate feedback is related to subordinate awareness of the supervisor's job; (h) supervisors tend to rate more favorably subordinates from the same nationality or race; (i) organizations should consider culture in terms of human resource development; and (j) variables that affect perceptions of ratees include age, power, pregnancy, and smoking
\end{abstract}

habits. These findings reflected the following five trends: (a) quantitative studies that investigated counterrational dimensions in the performance appraisal process, (b) quantitative studies that investigated interaction effects between rater and ratee characteristics, (c) quantitative studies that investigated preferences of raters and ratees, (d) quantitative studies that investigated communication transactions, and (e) quantitative studies that investigated international applications. The researcher recommends continued research in the areas of counterrational dimensions, interaction effects, participant preferences, communication transactions, and international applications of the performance appraisal process.

Key words: Performance appraisals; Performance evaluations; Performance feedback; Organizational communication; Corporate communication

Wanguri, D. M. (2014). A Review, an Integration, and a Critique of Cross-Disciplinary Research on Performance Appraisals, Evaluations, and Feedback: 1990-2000. Higher Education of Social Science, 7(1), 1-13. Available from: URL: http://www.cscanada.net/index.php/hess/article/view/4925 DOI: http://dx.doi.org/10.3968/4925

\section{INTRODUCTION}

During a trip to Seoul, South Korea, in 2002, I picked up the Thursday, July 18, 2002, English edition of JoongAng Ilbo, Korea's leading national newspaper. Always interested in performance feedback, I read with great interest an article by Pyo Jae-yong entitled "Risks of Performance-Based Pay: Report Warns of Individualism at Team's Expense". Here is an excerpt from that article:

Performance-based salaries and promotions can harm companies by encouraging extreme individualism and placing results ahead of process. In a report released on Wednesday, Samsung Economic Research Institute says that a number of companies that adopted performance-based systems following the financial 
crisis are suffering from some negative side effects. One Japanese firm that opted for promotion-based rewards was disappointed by the results. Three years after adopting annual salary reviews for mid- and upper-level managers in 1997, Sawai Pharmaceutical Co. dropped the plan, which, the firm said, focused excessively on individual performance, to the detriment of team spirit. ... The downside of adopting a performancebased system is more visible in domestic firms, the report says, because of their family-oriented culture. The report also mentions that chief executives of American firms were involved recently in account manipulation, inflated profit reports and sales to secure stock options and bonuses. The equal monetary rewards that each member of Korea's national soccer team received after the World Cup is a good example of maintaining a balance in rewards for individual and collective performance, the report says. The report says that a performance-based system most likely to be successful is one that is introduced gradually with thorough preparation and harmonization between collective and individual performances. It recommends use of both monetary and nonmonetary rewards, strong top leadership and clear presentation of policies regarding the changes. (Jae-yong, 2002, p.6)

For years now, performance ratings and pay-forperformance have dominated government and business circles in the United States (Brumback, 1993). Pay-forperformance, according to Coens and Jenkins (2000, p.161), is driven by primarily individualistic beliefs, such as the following: (a) I am a much better performer than others; (b) when I get the job done, it's the result of my hard work and excellent skills; (c) others do not work as hard or as well as I do; (d) my employer can recognize and distinguish the contribution of my performance versus what is caused by the system or others; (e) based upon months or a year of performance, an employer can distinguish good workers from the mediocre and subpar; and (f) the difference in performance between one employee and another is largely attributable to greater effort, skill, and commitment.

However, the preceding excerpt from JoongAng Ilbo clearly demonstrates that support for this practice is not universal. While pay-for-performance may attain success in some countries, in other countries, particularly in excolonial societies, its implementation and maintenance may be constrained by such factors as the rigidity of the structures under which the services operate and the cultures of the institutions themselves (Bissessar, 2000).

Performance appraisals remain a phenomenon in the life of most organizations in the United States however. It is not uncommon for organizations to target supervisors and managers for performance management training, which can include such topics as performance concerns, effective performance appraisals, motivation and morale, and change management (Biddle, 2006). As a process that is inherently communicative in nature, performance appraisals and the media through which they are transmitted are essential elements in creating a positive work environment.

Organizational communication scholars view this process as a microlevel information flow that occurs within the boundaries of most formal organizations in the United States; many practitioners, on the other hand, view it as a necessary evil in institutional and corporate life. Regardless of one's perspective, however, it is a fixture that shows no signs of disappearing from formal organizations. Because it is one of the most pervasive and necessary phenomena in the workplace, it continues to demand the attention of researchers and practitioners alike. (Wanguri, 1995, pp.267-268)

Given the importance and prominence of the performance appraisal process within the workplace, this essay seeks (a) to review and integrate cross-disciplinary empirical research published between 1990 and 2000 on the topic of performance appraisals, evaluations, and feedback in general; (b) to cull from this research those studies that focus specifically on communication phenomena within this process; and (c) to critique this literature and offer suggestions for future research.

\section{BACKGROUND}

In a review of cross-disciplinary research that was published between 1980 and 1990 on performance appraisals, evaluations, and feedback, Wanguri surveyed a total of 113 empirical studies and summarized research on rating instruments, raters, and ratees accordingly: (a) organizations use collaborative instruments to evaluate professional and managerial personnel and traditional instruments to evaluate hourly and nonexempt personnel; (b) organizations prefer to use $\mathrm{MBO}$ and BOS instead of trait scales; (c) the relative accuracy of BARS is inconclusive; (d) assessment centers should represent only one criterion for managerial promotion; (e) training in the proper use of rating instruments is essential in order to minimize error; (f) multiple rater performance appraisals are more effective than single rater appraisals; (g) the degree of agreement between self-rating and others' ratings is inconclusive; (h) interrater agreement is strong between peer- and supervisory ratings; (i) subordinate appraisals of managers are valid measures of supervisory performance; $(\mathrm{j})$ rater characteristics (e.g., organizational tenure, age, gender, style of dress) interact with ratee characteristics to affect performance ratings; (k) managerial ratees' perceptions of the formal performance appraisal are divided; (1) the perceived fairness of the performance appraisal process is influenced by the superior-subordinate relationship and this perception influences views about compensation; and (m) performance feedback is positively correlated with ratee job satisfaction (1995).

In addition Wanguri recommended the following agenda for future research: (a) generate quantitative studies that investigate the counterrational dimensions of the formal performance appraisal process; (b) develop quantitative studies that further investigate interaction effects between rater and ratee characteristics; (c) develop studies that investigate the preferences of raters and 
ratees toward components in the performance appraisal process; and (d) develop studies that further investigate communication transactions within the framework of the performance appraisal process. The current essay thus seeks to build on that study by reviewing more recent cross-disciplinary research, highlighting communicationspecific research, critiquing this literature, and offering an agenda for future research.

\section{REVIEW OF LITERATURE}

A review of the literature was conducted using the following sources: (a) Personnel Management Abstracts (1990-2000), and (b) EBSCO (NCA Collection). Articles included in this review of literature met the following criteria: (a) they were referenced in one of the preceding indices under the heading of performance appraisal, performance evaluation, or performance feedback; (b) they were empirical in nature; and (c) they were accessible (Some of the journals, such as the Asia Pacific HRM, were inaccessible). Ninety-eight empirical studies were identified and met these criteria.

\subsection{Performance Appraisal Systems and Practices}

In general larger establishments with more than 1000 employees are more likely to have alternative work organization practices, which may include worker teams, total quality management (TQM), quality circles, peer review of employee performance, employee involvement in the firm's technology and equipment purchase decisions, and job rotation (Gittleman, Horrigan, \& Joyce, 1998). On the other hand, very small establishments with fewer than 50 employees are less likely to have such practices. In many cases, the lack of technical resources and an absence of expertise are the primary barriers to the adoption of any type of performance appraisal system (Roberts, 1994a).

Satisfaction with appraisal is positively correlated with employee participation in the appraisal process, development of action plans to remediate performance weaknesses, and the existence of a formal rater training program, as well as closeness of supervision and quality of the leader-subordinate exchange (Dobbins, Cardy, \& Platz-Vieno, 1990) while it is negatively correlated with role ambiguity and role conflict. In addition there is fairly strong support for the effects of a due process appraisal system-which involves adequate notice, fair hearing, and judgment based on evidence-on the reactions of employees and managers, who as a result generally perceive greater accuracy and fairness in the appraisal system and greater satisfaction with appraisals (Taylor, Tracy, Renard, Harrison, \& Carroll, 1995). Such performance evaluations should be meaningful, should include positive aspects as well as areas for improvement, should address future expectations, and should be an open forum for two-way communication (Clifford, 1999). Finally employee "voice", as reflected through opportunities for participation, goal setting, and feedback, is also a feature of an effective performance appraisal system (Roberts, 1994b; Korsgaard \& Roberson, 1995). Interestingly however, it seems that in the implementation of performance appraisal systems, there is little difference in ratings that raters assign in agencies with high levels of investment (e.g., training, materials, and other resources) and those that raters assign in agencies with low levels of investment (Balfour, 1992).

Performance appraisal is the most heavily litigated personnel activity in equal employment opportunity law (Bernadin, Hennessey, \& Peyrefitte, 1995). In many cases managers believe the appraisal process is reasonably effective while subordinates view the process as ineffective (Longenecker \& Nykodym, 1996). In general an employer that conducts periodic, welldesigned performance evaluations with formal appraisal interviews and makes personnel decisions based upon the performance appraisal is more likely to successfully rebut a claim of discriminatory conduct (Miller, Kaspin, \& Schuster, 1990). Additional findings indicate that organizations which use job analysis, provide written instructions, and allow employees to review appraisal results are more likely to experience favorable outcomes in legal proceedings, when they do occur (Werner \& Bolino, 1997). It actually seems that most performance appraisal systems are designed in accordance with the literature; however the administration of these systems is often problematic (Roberts, 1995).

International studies: Several studies have examined performance appraisal systems and practices abroad. In Great Britain for example, there is evidence of a substantial erosion of the role of trade unions as bargaining agents in pay determination with the emergence of performance-related pay or PRP (Heery, 1997); of the collectivistic impact of union involvement (Healy, 1997); of the effect of a high-performance work system on teamwork and the distribution of training (Whitfield, 2000); and of the adoption of formal appraisal systems in universities (Townley, 1999). In India, there is evidence that in high-performance work systems, objective and equitable performance appraisal practices are used for both evaluative and developmental purposes (Amba-Rao, Petrick, Gupta, \& Embse, 2000). Finally in Ireland, there is evidence that performance-related pay systems are most commonly used in non-union companies among managerial/professional grades while collective bargaining is the primary means of determining levels of pay increases (Gunnigle, Turner, \& D'Art, 1998).

To summarize, empirical research on performance appraisal systems and practices indicates that:

(a) Effective performance appraisal systems feature opportunities for employee "voice" (i.e., employee participation in the appraisal process). 
(b) PRP systems are being implemented with increasing frequency internationally.

\subsection{Rating Instrument}

Although objective and subjective performance measures should not be used interchangeably (Bommer, Johnson, Rich, Podsakoff, \& MacKenzie, 1995), differences in rating scale formats seem to have little impact on the reliability or validity of performance ratings (Tziner, Joanis, \& Murphy, 2000). However, different methods of obtaining and recording information about job performance may be more or less conducive to the developmental uses of performance appraisal.

In reality all types of appraisal systems are subject to rating distortion. The greater the criterion specificity (i.e., behaviors, results, or outcomes, as opposed to traits), however, the greater the probability of a fair and accurate appraisal, thereby decreasing the chances of age, race, or gender bias (Bernadin, Hennessey, \& Peyrefitte, 1995). In addition, distributional ratings, which reflect meaningful fluctuations of ratee performance within dimensions, contain substantially less measurement error than more typical global rating scales (Woehr \& Miller, 1997). Finally greater leniency bias is found for administrativebased performance appraisal systems, compared to research-based appraisal systems (Harris, Smith, \& Champagne, 1995). Correcting rating errors requires rater training, observational techniques such as diarykeeping, and a comprehensive psychometric assessment of ratings (Roberts, 1998).

Conventional assessments of performance include graphic rating scales (GRS), behavioral observation scales (BOS), behavioral expectation scales (BES), behaviorally anchored rating scales (BARS), mixed standards scales (MSS), and trait scales. Also included are objectivesbased performance appraisal systems (Daley, 1990). BOS are superior to BARS in terms of ratee satisfaction, goal specificity and observability, and ratee perceptions of goals. BOS are significantly better than GRS only in terms of goal specificity (Tziner, Joanis, \& Murphy, 2000).

A more recent index is total performance effectiveness (TPE), which can be used to express the effectiveness of performance in many jobs, particularly in situations where there is not much differentiation among employees in their average performance levels (Kane, 1996). Performance distribution assessment (PDA) is another method of performance appraisal that has revealed significant correlations between the PDA-derived performance measures and objective measures of job performance, differential correlations between ability and the multiple PDA-derived performance measures, and equivalent levels of rating accuracy for the PDA and the evaluative measure of typical performance (Deadrick $\&$ Gardner, 1997). In addition the correlated uniqueness model (CU) was examined and is the most appropriate for multitrait-multirater (MTMR) performance appraisal data
(Conway, 1996). Finally a model of the latent structure of performance ratings based on Wherry's theory of rating was tested but results failed to confirm this model (Lance, 1994).

International studies: Several studies have examined the use of rating instruments abroad. Researchers in the Netherlands investigated three types of appraisal instruments - trait scales, BOS, and BES - and found an overall pattern of responses that parallels that pattern found with Americans. People prefer BOS to trait scales and to BES because BOS provide users with the most accurate conception of the job (Wiersma, van den Berg, \& Latham, 1995). In addition research conducted in four southeast Asian countries (i.e., Indonesia, Malaysia, Philippines, and Thailand) provides strong support for the presence of a divergence effect as an aid to helping multinational corporations develop effective control measures that increase the likelihood of business success in this region (Paik, Vance, \& Stage, 2000). Finally, research conducted in Russia indicates that better performing Russian firms gain a competitive advantage by using more sophisticated environmental scanning systems (Elenkov, 1997).

To summarize, empirical research on rating instruments indicates that:

(a) BOS are superior to BARS and GRS in terms of goal specificity.

(b) All types of appraisal systems are subject to rating distortion and may include validity, reliability, and rating errors.

\subsection{Rater}

Most past research has used validity, reliability, and rating error measures as criteria in evaluating appraisal systems. Although such psychometric considerations are certainly important, they are not sufficient criteria to comprehensively evaluate the quality of performance appraisal. One additional consideration should be user acceptance of the performance appraisal system (Hedge $\&$ Teachout, 2000; Bettenhausen \& Fedor, 1997). Such a consideration has become even more important with the increased popularity and use of 360-degree ratings.

Multirater or 360-degree feedback systems are characterized by the evaluation of an individual's performance from multiple raters and from multiple levels. Although specific procedures may vary, typically the individual is rated by others who interact frequently with the individual, who are knowledgeable about the individual's performance, and whose opinions are valued by the individual. The most common procedure is to include peers, subordinates, and bosses in addition to self-ratings, but raters outside the organization, such as customers or suppliers, may also be included. Multirater feedback programs differ from traditional appraisal programs in several ways. They are used most frequently to enhance personal development and 
growth, as opposed to salary administration, promotions, or other administrative decisions; they provide ratings anonymously, with the exception of the immediate supervisor; and they are not accompanied by face-to-face discussion. This process operates on the premise that a rating from each rater, regardless of the level, captures unique rating variance (Mount, Judge, Scullen, Sytsma, \& Hezlett, 1998).

Upward ratings: Understandably 360-degree ratings can be a highly political process, particularly when they involve upward ratings (i.e., the process by which supervisors receive ratings from multiple subordinates). A leader's acceptance of feedback from subordinates and peers is significantly related to his or her overall ratings, and to the leader's perceptions of the usefulness of the subordinate feedback. It appears that as overall ratings or feedback become less positive, leaders are less likely to view the feedback as accurate. As the level of ratings decreases, leaders may try to discount information from peers and subordinates rather than accept it as accurate, which could negate some of the potential developmental benefits of the 360-degree feedback. To ensure that leaders in a 360-degree feedback system participate fully in the 360-degree feedback system, organizations should ensure that subordinates are thoroughly trained in the rating process and that leaders perceive that training as enhancing subordinates' rating skills rather than just informing subordinates about the rating process (Facteau, Facteau, Schoel, Russell, \& Poteet, 1998).

In addition, findings indicate that upward appraisals are believed to produce more positive outcomes and fewer negative outcomes than peer appraisals (Bettenhausen \& Fedor, 1997); that those who choose to participate in upward appraisals generally perceive the upward feedback questions as relevant, perceive the time required as appropriate, and feel they possess knowledge of the ratee's performance (Westerman \& Rosse, 1997); that in ratings for a focal leader there is substantial within-group variation (Avolio, Yammarino, \& Bass, 1991); and that organizations implementing upward appraisals should ensure complete response anonymity and confidentiality (Antonioni, 1994). Regarding subordinate appraisal of managers (SAM), findings indicate that SAM appears to have high potential in terms of user acceptance under certain conditions: (a) when subordinates are aware of the requirements of the supervisor's job; (b) when subordinates are asked to rate only the people-oriented dimensions of their boss's performance (e.g., leadership, oral communication, coordination of team efforts, interest in subordinates, performance feedback ability, providing work guidance, composure and self-control, interpersonal relations); (c) when the accuracy and fairness of SAM are carefully monitored; and (d) when subordinate ratings are used primarily for developmental purposes (McEvoy, 1990). The extent to which SAM appraisal system participants accept its parameters and believe in its validity and accuracy can determine the system's effectiveness (Ash, 1994). Finally findings indicate that managers whose initial level of performance was rated low had improved two and one-half years after an upward feedback program was implemented (Reilly, Smither, \& Vasilopoulos, 1996); that managers who held feedback sessions to discuss their upward feedback with their direct reports improved more than other managers (Walker \& Smither, 1999); and that in most cases self-ratings prior to feedback are higher than subordinate ratings (Atwater, Waldman, Atwater, \& Cartier, 2000).

Downward ratings: However, supervisory evaluations of subordinates (i.e., downward ratings) can be equally political. Performance appraisal by executives, for example, is undisputedly a political process. It is often a process in which a deliberate attempt is made on the part of a higher-ranking executive to enhance, control, or protect self- or organizational interests via the appraisal of subordinate executives. Especially in the executive appraisal process for example, one can draw the following conclusions: (a) politics is prevalent in appraisal and the higher one rises in the organization, the more political the appraisal process becomes; (b) because of the dynamic, ambiguous nature of managerial work, appraisals are susceptible to political manipulation; (c) performance is not necessarily the bottom line in the executive appraisal process; (d) senior executives have extraordinary latitude in evaluating subordinate executives performance; and (e) executive appraisal is a "political tool" used to control people and resources (Gioia \& Longenecker, 1994).

Additional findings indicate that leaders who are seen as challenging the status quo and encouraging subordinates' independent action are rated lower by their supervisor managers although their subordinates may rate them higher (Salam, Cox, \& Sims, 1997); that supervisors generally have the greatest influence on rater compliance with rating procedures (Robinson, Fink, \& Allen, 1996); that highly influential supervisors generally rate those employees that are highly compliant more favorably (Ralston \& Waters, 1996); that assignees are generally rated more favorably by supervisors from the same nationality or race (Caligiuri \& Day, 2000; Mount, Sytsma, Hazucha, \& Holt, 1997); and that there is a tendency for supervisors to inflate subordinate ratings associated with high rater negative affectivity, low documentation of subordinates' work behaviors, and high appraisal visibility (Fried, Levi, Ben-David, \& Tiegs, 1999). Interestingly there were three additional studies that focused specifically on communication issues. Most recently the first study examined the effects of coworker information on supervisory perceptions and ratings of performance, and it concluded that when the information sources were consistent (i.e., favorable direct performance information/favorable coworker performance information or unfavorable direct performance information/ unfavorable coworker performance information), raters 
perceived the indirect performance information provided by the coworker as more accurate, as more useful, and as leading to greater confidence in the assigned performance rating (Thorsteinson \& Balzer, 1999). The second study investigated seven types of "turning points" (i.e., patterns of change within relationships) in the academic chairfaculty relationship, and designated the performance evaluation as one type, in addition to recognition, support, trustworthiness, job interference, outside interaction, and interpersonal discussion (Barge \& Musambira, 1992). The final study demonstrated a relationship between a rater's decision rule orientation and verbal planning complexity. Simple verbal plans for conducting the negative appraisal performance appraisal were characterized by (a) presenting only the manager's or organization's perspective; (b) demanding that the problem be resolved immediately; (c) proposing a specific, inflexible alternative for problem resolution; and (d) advancing dichotomous outcomes in the form of ultimatums. On the other hand, complex verbal plans (a) considered the problem from the manager's, organization's, and employee's point of view; (b) examined similarities and differences in these three perspectives; (c) viewed employee behavior and organizational demands in degrees of reasonableness and appropriateness; (d) used perspectives to understand the origin and meaning of the employee's behavior; (e) proposed multiple problem solutions; and (f) described interview outcomes in degrees of improvement (Plax, Beatty, \& Feingold, 1991).

Peer ratings: Multirater feedback systems can also include peer ratings. Findings indicate that peer rating systems using more experienced and educated raters increase perceptions of rating system fairness primarily via higher perceptions of competence, via increased perceptions of correctability, and via decreased perceptions of bias. Essentially rater competence and rating correctability will positively influence fairness perceptions (Barclay \& Harland, 1995). In addition findings indicate that four factors contribute to peer review system acceptance: (a) stressing the developmental side of the peer review system; (b) encouraging employees to feel that they have "voice" when being appraised; (c) helping raters to see the value of their efforts; and (d) promoting the feedback as a valuable tool for performance improvement (Fedor, Bettenhausen, \& Davis, 1999). Finally, context, design, and implementation must all be aligned in order for peer evaluation to work well (Peiperl, 1999) and a significant interaction exists between rating purpose and accountability on rating delay but not on peer-rating inflation (Beckner, Highhouse, \& Hazer, 1998).

Self ratings: A fourth dimension of multirater feedback systems, in addition to upward ratings, downward ratings, and peer ratings, is self rating. This method typically involves the formal evaluation of one's own performance, which is used to supplement performance appraisals made by supervisors or others. Self-appraisal (SA) methods have been recommended for both developmental and administrative evaluations but the effects of self-appraisal may be more complex than typically represented in the literature (Roberson, Torkel, Korsgaard, Klein, Diddams, \& Cayer, 1993). Individuals are more likely to agree with feedback and incorporate it into subsequent self-evaluations if the feedback is consistent with their self-appraisals (Korsgaard, 1996). In addition, self-monitoring (SM), a personality variable, is positively related to assessors' and supervisors' ratings of interpersonal effectiveness but unrelated to ratings of business competence (Warech, Smither, Reilly, Millsap, \& Reilly, 1998).

Findings also indicate significant profile agreement between self- and the average of subordinate ratings (London \& Wohlers, 1991); variance in magnitudes of the correlations between predictors and leader behavior, as well as between leader behavior and performance (Atwater \& Yammarino, 1992); and more congruence between self-appraisals and supervisor appraisals when the subordinates perceive that they have more knowledge about the performance appraisal system (Williams \& Levy, 1992). Finally, regarding self-other ratings, findings lend support for the importance of simultaneously considering self-ratings and other ratings in explaining managerial effectiveness (Atwater, Ostroff, Yammarino, \& Fleenor, 1998); the usefulness of these ratings as a useful supplement to traditional performance appraisals conducted by supervisors (Cheung, 1999); and the effects of interrater and self-other agreement on performance improvement following upward feedback (Johnson \& Ferstl, 1999). Other important issues related to the role and performance of the rater in the performance appraisal process are the performance feedback purpose (Burke, 1996; Jawahar \& Williams, 1997); implicit stress theory (Fernandez \& Perrewe, 1995); cognitive categorization processes (Lance, Woehr, \& Fisicaro, 1991); global evaluations (Woehr, 1992); dyadic performance ratings (Delery, Gupta, Jenkins, \& Walker, 1998); the importance of goal achievement as a leadership role (Hooijberg \& Choi, 2000); interpersonal affect (Varma, Denisi, \& Peters, 1996); response rates (Church, Rogelberg, \& Waclawski, 2000), assessment centers (Lowry, 1991; Lowry, 1996); and preferences of personnel professionals in the development of appraisal systems (Roberts \& Pavlak, 1996).

International studies: Several studies have examined the role of the rater abroad. Researchers in Australia examined the impact of the introduction of a developmental appraisal program in an Australian federal agency and found benefits to managers and employees through more favorable employee responses of greater satisfaction with feedback and performance improvement (Tharenou, 1995). In addition researchers in Canada investigated the extent to which organizational political 
considerations affect performance appraisals in such ways as inflated performance ratings of subordinates and other deliberate manipulations of ratings for political purposes (Tziner, Latham, Price, \& Haccoun, 1996) while researchers in Hong Kong and Great Britain investigated the extent to which actual practices and employee preferences regarding performance appraisal are in alignment (Snape, Thompson, Yan, \& Redman, 1998). Furthermore, researchers in Korea found goal setting and career discussions are positively related to employee satisfaction with the review and that goal setting is also positively related to the employee's utility of the review (Lee \& Son, 1998) while researchers in Taiwan found that Chinese employees rate their own job performance lower than their supervisors evaluate their performance, reflecting a modesty bias, a collectivistic culture hypothesis, and the importance of considering culture in terms of human resource management (Farh, Dobbins, $\&$ Cheng, 1991). Finally, in a cross-cultural study of differences in upward ratings in 10 countries (i.e., France, Germany, Poland, U.S., Mexico, Brazil, Singapore, Malaysia, Hong Kong, and Thailand), researchers found differences in terms of power distance, individualism, feminism, and uncertainly avoidance (Adsit, London, Crom, \& Jones, 1997) and in a second study of managers based in Belgium, researchers found that international managers in high power positions were evaluated according to parent company standards (as opposed to local or worldwide standards), in order to guarantee internal consistency (Janssens, 1994).

To summarize, empirical research on raters indicates that:

(a) Multirater, SAM, and peer review feedback programs should be used most frequently for developmental purposes and performance improvement.

(b) Perceived accuracy of performance feedback is one of the most important components of the evaluation process; it may be influenced by overall ratings, acceptance of appraisal system parameters, and consistency of information sources.

(c) Acceptance of subordinate feedback is high when subordinates are aware of the requirements of the supervisor's job as well as that person's actual job performance.

(d) Supervisors tend to rate more favorably subordinates from the same nationality or race.

(e) Organizations should consider culture in terms of human resource development.

\subsection{Ratee}

It is likely that more organizational members have had the experience of being rated, or evaluated, in the workplace than those that have had experience of rating others. For this reason, this aspect of the performance appraisal is particularly interesting. Several variables affect rater perceptions of ratees. As expected, age and gender are generally influential but pregnancy and smoking habits on the part of the ratee are also powerful factors. More specifically, in professional positions, age norms are likely to exist for various jobs, and individuals are generally able to agree as to what those norms are. In such settings, there is often a negative correlation between ratee age and rater evaluation of that person's technical and overall job performance. Since perceptions of performance will generally decline for relatively older workers in an entrylevel job, age is negatively related to job performance evaluations (Saks \& Waldman, 1998). Regarding gender, subordinates are influenced more by the leader's power than by the leader's gender. These findings held irrespective of the subordinate's gender or the gender combination of the leader-subordinate dyad. Hence power, not gender, appears to be the critical variable in the evaluation process (Ragins, 1991). For pregnant women in the workplace, perceptions, not official policies, may cause the greatest difficulties. Pregnant women may indeed face additional workplace discrimination above and beyond any gender bias that may already exist. With the "pregnancy bias effect", pregnant women are seen as overly emotional, often irrational, physically limited, and less committed to their jobs; hence pregnant women are assigned with a remarkably high degree of consistency lower performance ratings than non-pregnant women (Halpert, Wilson, \& Hickman, 1993). Finally, as a social stigma, smoking also affects ratees. Negative bias toward the smoker is likely to be amplified by the simultaneous interplay of the conduct nature of the stigma, the observability of the behavior, and organizational policies requiring smokers to congregate in designated smoking areas away from areas where they are normally expected to perform their jobs. Even after controlling for known bias factors, such as age, gender, and race, employees who are perceived to be smokers are more likely to be rated lower by their supervisors in three measures of job performance (i.e., dependability, positive working relationships, and proper comportment) as well as the global measure of overall job performance (Gilbert, Hannan, \& Lowe, 1998).

Additional findings indicate that leader-member exchange (LMX) performance interaction contributes additional variance in ratings beyond that accounted for by actual performance (Duarte, Goodson, \& Klich, 1993); that perceived system knowledge (PSK) is an important predictor of both appraisal-related variables (i.e., reactions and fairness) and more general organizational variables (i.e., job satisfaction and organizational commitment) (Levy \& Williams, 1998); that contrast effects influence ratings of ratees when there is variation in performance within and among assessees (Gaugler \& Rudolph, 1992); and that video-based situational tests can provide valid predictions of job performance (Weekley \& Jones, 1997). Interestingly there was an additional study that focused specifically on communication issues. It presented seven 
types of information that organizational newcomers need during their socialization; these information types are technical, referent, social, appraisal, normative, organizational, and political. It concluded that newcomers regard appraisal and referent information as more useful than the other types of information and that an important priority for newcomers is to learn about organizational politics (Morrison, 1995).

International studies: Several studies have examined the role of the ratee abroad. More specifically researchers in Canada examined predictors of employee preferences for nontraditional performance appraisal and found that aspects of the individual users, their work design, and the current appraisal context can predict preferences (Waldman, 1997). In Hong Kong, researchers explored the effects of a process-oriented and group-oriented appraisal system and found that compared to the results focus, the process focus had a more positive and significant effect on appraisal satisfaction, expected improvement, and actual results. However, no differences were found between the effects of team and individual bases of comparison (Lam \& Schaubroeck, 1999). Also in Hong Kong, researchers found strong support for a combined model of perceived fairness and accuracy of performance evaluation, which is influenced by the Chinese cultural characteristics of paternalism and personalism (Lee \& Akhtar, 1996). Finally researchers in New Zealand found that performance planning and goal-setting in performance appraisal had favorable consequences for employee attitudes (Taylor \& Pierce, 1999) and researchers in the United Kingdom found that performance appraisal is perceived as being related to a "hidden agenda", "image", and "subjectification" (Coates, 1994).

To summarize, empirical research on ratees indicates that:

Variables that affect perceptions of ratees include ratee age, power, pregnancy, and smoking.

\section{EMPIRICAL STUDIES ON COMMUNICATION PHENOMENA IN PERFORMANCE APPRAISALS, EVALUATIONS, AND FEEDBACK}

The most straightforward and obvious strategy for distinguishing those empirical studies focusing on communication phenomena within the performance appraisal process, is to examine articles that are cited in EBSCO (NCA Collection). This search only produces four articles however, two of which are nonempirical and are related to evaluation and criticism in the context of performance studies, an interest area of communication studies (Park-Fuller \& Pelias, 1995; Long, 1991). However, the remaining two articles are empirical and do focus on the performance appraisal process, examining verbal complexity in performance appraisal interviews (Plax, Beatty, \& Feingold, 1991) and the role of the performance evaluation as a turning point in chair-faculty relationships (Barge \& Musambira, 1992). An examination of Communication Abstracts (1990-2000) produces an expanded list of additional articles and studies. However, many of them, like some of those referenced in EBSCO, also have a different focus than performance appraisal, evaluation, and feedback of employees in the workplace, by examining such topics as speech preparation (Daly, Vangelisti, \& Weber, 1995), television advertising (Kover, Goldberg, \& James, 1995), presidential politics (Pan \& Kosicki, 1997; Owen, 1997), internet telephone systems (Foo \& Hui, 1998), and information technology (Peterson, 1998).

A second strategy for distinguishing communication phenomena in the literature is to conduct a content analysis of the remaining studies. Using this strategy, one finds that in a number of empirical studies published in other types of journals, researchers examine communication phenomena. In one study for example, published in the Journal of Organizational Behavior, Thorsteinson and Balzer concluded that consistency in various direct and indirect information sources about employees leads to perceptions of increased accuracy, usefulness, and confidence in information from indirect sources (1999). The Journal of Organizational Behavior is a journal that focuses on research and theory in all topics associated with occupational/organizational behavior, including motivation, work performance, equal opportunities at work, job design, career processes, occupational stress, quality of work life, job satisfaction, personnel selection, and job analysis. In a second study, which was published in Management Communication Quarterly, Morrison concluded that organizational newcomers generally regard appraisal and referent information as most useful in the workplace (1995). Management Communication Quarterly is an international journal that provides an interdisciplinary forum for scholarship relating to language studies, sociology, management, psychology, communication, and organizational behavior. These studies reflect that cross-disciplinary researchers do observe communication as a variable in some of their studies.

It must be noted that the limitations of the present study do affect the number of communication studies cited in this essay. More specifically, the exclusion of research that is not indexed in Personnel Management Abstracts and EBSCO's NCA Collection; the exclusion of research that is nonempirical in nature; and the exclusion of research that is inaccessible, eliminate a number of journals and studies focusing on communication phenomena. Since this essay includes only a sample of research published on the topic of performance appraisals and since the citations do not include research published prior to 1990 and later than 2000, this survey of literature 
is noncomprehensive. Although this essay offers valuable insight into trends that characterize current research on the topic of communication in performance appraisals, evaluation, and feedback, it addresses only a sample of such research.

Therefore, a third strategy for distinguishing communication phenomena in the literature is to go beyond the perimeters of this particular study. In so doing, one encounters additional research in such journals as the Journal of Business Communication. As a medium that addresses all areas of business communication, including but not limited to business composition/ technical writing, information systems, international business communication, management communication, and organizational/corporate communication, this journal contains several relevant studies involving communication phenomena. The topics covered in these studies include the relationship between three types of appraisal feedback-performance improvement emphasis, corporate goal emphasis, salary informationand managerial motivation and appraisal objectivity (Goodson, McGee, \& Seers, 1992); the relationship between salesperson communication style variables and sales performance (Dion \& Notarantonio, 1992); and the relationship between leader and member assessments of leader performance (Kolb, 1995). A fourth article in this journal evaluated performance appraisal instrument dimensions, but utilized a qualitative construct analysis in a field setting (Williams \& Hummert, 1990).

\section{CRITIQUE AND FUTURE RESEARCH}

Taken as a whole, this essay does reflect a number of trends in research generated between 1990 and 2000. The first four trends are directly related to aforementioned suggestions for future research (Wanguri, 1995); the fifth is an additional trend.

First, research during this decade did reflect more quantitative studies that investigated counterrational dimensions in the performance appraisal process. Although earlier studies approached this process as a highly rational and systematic activity, a number of studies during this decade addressed performance appraisal as a highly political engagement, where performance is not necessarily the bottom line and where rating inflation occurs regularly. To the extent that rating inflation can reflect political behavior in organizations and can include "activities that are not required as part of one's organizational role but that influence, or attempt to influence, the distribution of advantages and disadvantages with the organization" (Farrell \& Petersen, 1982, p.405), it may be viewed as a form of organizational misbehavior (OMB), referring to "acts in the workplace that are done intentionally and constitute a violation of rules pertaining to such behaviors" (Vardi \& Weitz, 2004, p.3). Although rating inflation may seem rather innocuous compared to other forms of misbehavior, Vardi and Weitz make the following observation:

Such behaviors range a full spectrum from minor to serious-
a mere perception of violation of the psychological contract,
minor workplace incivility, insulting behaviors, workplace social
undermining, theft of company assets, acts of destructiveness,
vandalism and sabotage, substance abuse while at work, and
aggression perpetuated against fellow employees or toward the
organizations. (2004, p.4)

Continued research on rating inflation is certainly one area that merits further investigation; an additional seemingly uninvestigated area of interest is the occurrence of rating deflation in the workplace.

Second, research during this decade did examine interaction effects between rater and ratee characteristics. These studies focused on the interaction between rater and ratee nationality, race, and gender. The possibilities of such research are truly limitless however. Being able to investigate the effects of such interactions as those between raters who are smokers and ratees who are smokers, for example, would certainly yield interesting findings. Alternatively, having the opportunity to investigate the effects of such interactions as those between raters who are pregnant and ratees who are pregnant, for example, would yield equally interesting findings. Continued research on interaction effects between rater and ratee characteristics is essential.

Third, research during this decade did reflect preferences of raters and ratees regarding the performance appraisal process. These studies focused on preferences of personnel professionals in the development of a performance appraisal system and on the preferences of employees regarding nontraditional performance appraisals. In order for all participants to perceive the performance appraisal process as fair, all parties must have a voice in the process. Continued research on rater and ratee preferences is essential.

Fourth, research during this decade did reflect increased attention on communication transactions in the performance appraisal process, as reflected in the preceding section. Multiple studies in communication, business, and psychology journals examined this phenomenon. Continued research on communication phenomena is essential.

Finally, research during this decade reflected a preponderance of international interest in the performance appraisal process. The increased interest in this process abroad, in such diverse settings as Great Britain, India, the Netherlands, Indonesia, Thailand, Russia, Australia, Korea, Brazil, and Germany, is noteworthy, considering the fact that performance appraisal has been a phenomenon largely associated with the United States. Continued research on the performance appraisal process in international settings is essential; future research should continue to compare these findings with trends in the 


\section{United States.}

\section{REFERENCES}

Adsit, D. J., London, M., Crom, S., \& Jones, D. (1997). Crosscultural differences in upward ratings in a multinational company. International Journal of Human Resource Management, 8(4), 385-401.

Amba-Rao, S. C., Petrick, J. A., Gupta, J. N. D., \& Embse, T. J. V. (2000). Comparative performance appraisal practices and management values among foreign and domestic firms in India. International Journal of Human Resource Management, 11(1), 60-89.

Antonioni, D. (1994). The effects of feedback accountability on upward appraisal ratings. Personnel Psychology, 47(2), 349356.

Ash, A. (1994). Participants' reactions to subordinate appraisal of managers: Results of a pilot. Public Personnel Management, 23(2), 237-256.

Atwater, L. E., Ostroff, C., Yammarino, F. J., \& Fleenor, J. W. (1998). Self-other agreement: Does it really matter? Personnel Psychology, 51(3), 577-598.

Atwater, L. E., Waldman, D. A., Atwater, D., \& Cartier, P. (2000). An upward feedback field experiment: Supervisors' cynicism, reactions, and commitment to subordinates. Personnel Psychology, 53(2), 275-297.

Atwater, L. E., \& Yammarino, F. J. (1992). Does self-other agreement on leadership perceptions moderate the validity of leadership and performance predictions? Personnel Psychology, 45(3), 141-164.

Avolio, B. J., Yammarino, F. J., \& Bass, B. M. (1991). Identifying common methods variance with data collected from a single source: An unresolved sticky issue. Journal of Management, 17(3), 571-587.

Balfour, D. L. (1992). Impact of agency investment in the implementation of the performance appraisal. Public Personnel Management, 21(1), 1-15.

Barclay, J. H., \& Harland, L. K. (1995). Peer performance appraisals: The impact of rater competence, rater location, and rating correctability on fairness perceptions. Group and Organization Management, 20(1), 39-60.

Barge, J. K., \& Musambira, G. W. (1992). Turning points in chair-faculty relationships. Journal of Applied Communication Research, 20(1), 54-77.

Beckner, D., Highhouse, S., \& Hazer, J. T. (1998). Effects of upward accountability and rating purpose on peerrater inflation and delay: A field experiment. Journal of Organizational Behavior, 19(2), 209-214.

Bernadin, H. J., Hennessey, Jr. H. W., \& Peyrefitte, J. (1995). Age, racial, and gender bias as a function of criterion specificity: A test of expert testimony. Human Resource Management Review, 5(1), 63-77.

Bettenhausen, K. L., \& Fedor, D. B. (1997). Peer and upward appraisals: A comparison of their benefits and problems.
Group and Organization Management, 22(2), 236-263.

Biddle, L. E. (2006, September 13). Performance management series. Message posted to DT_All_Users.

Bissessar, A. M. (2000). The introduction of new appraisals systems in the public services of the Commonwealth Caribbean. Public Personnel Management 29(2), 277-292.

Bommer, W. H., Johnson, J. L., Rich, G. A., Podsakoff, P. M., \& MacKenzie, S. B. (1995). On the interchangeability of objective and subjective measures of employee performance: A meta-analysis. Personnel Psychology, 48(3), 587-605.

Brumback, G. B. (1993). Sixteen elephants can't do what a change in law could. Public Personnel Management, 22(2), 237-242.

Burke, R. J. (1996). Performance evaluation and counseling in a professional services firm. Leadership and Organization Development Journal, 17(3), 21-26.

Caligiuri, P. M., \& Day, D. V. (2000). Effects of self-monitoring on technical, contextual, and assignment-specific performance: A study of cross-national work performance ratings. Group and Organization Management, 25(2), 154174.

Cheung, G. W. (1999). Multifaceted conceptions of self-other ratings disagreement. Personnel Psychology, 52(1), 1-36.

Church, A. H., Rogelberg, S. G., \& Waclawski, J. (2000). Since when is no news good news? The relationship between performance and response rates in multirater feedback. Personnel Psychology, 53(2), 435-452.

Clifford, J. P. (1999). The collective wisdom of the workforce: Conversations with employees regarding performance evaluation. Public Personnel Management, 28(1), 119-155.

Coates, G. (1994). Performance appraisal as icon: Oscar-winning performance or dressing to impress? International Journal of Human Resource Management, 5(1), 167-191.

Coens, T., \& Jenkins, M. (2000). Abolishing performance evaluations: Why they backfire and what to do instead. San Francisco, CA: Berrett-Koehler.

Conway, J. M. (1996). Analysis and design of multitraitmultirater performance appraisal studies. Journal of Management, 22(1), 139-162.

Daley, D. M. (1990). The Civil Service Reform Act and performance appraisal: A research note on federal employee perceptions. Public Personnel Management, 19(3), 245-251.

Daly, J. A., Vangelisti, A. L., \& Weber, D. J. (1995). Speech anxiety affects how people prepare speeches: A protocol analysis of the preparation processes of speakers. Communication Monographs, 62(4), 383-397.

Deadrick, D. L., \& Gardner, D. G. (1997). Distributional ratings of performance levels and variability: An examination of rating validity in a field setting. Group and Organization Management, 22(3), 317-342.

Delery, J. E., Gupta, N., Jenkins, Jr. G. D., \& Walker, B. C. (1998). Interdimensional correlations in individual and dyadic performance ratings. Journal of Organizational Behavior, 19(6), 577-587.

Dion, P. A., \& Notarantonio, E. M. (1992). Salesperson communication style: The neglected dimension in sales 
performance. Journal of Business Communication, 29(1), 63-77.

Dobbins, G. H., Cardy, R. L., \& Platz-Vieno, S. J. (1990). A contingency approach to appraisal satisfaction: An initial investigation of the joint effects of organizational variables and appraisal characteristics. Journal of Management, 16(3), 619-632.

Duarte, N. T., Goodson, J. R., \& Klich, N. R. (1993). How do I like thee? Let me appraise the ways. Journal of Organizational Behavior, 14(3), 239-249.

Elenkov, D. S. (1997). Environmental scanning systems and performance: An empirical study of Russian companies. Journal of Management Development, 16(2-3), 111-124.

Facteau, C. L., Facteau, J. D., Schoel, L. C., Russell, J. E. A., \& Poteet, M. L. (1998). Reactions of leaders to 360-degree feedback from subordinates and peers Leadership Quarterly, 9(4), 427-448.

Farh, J., Dobbins, G. H., \& Cheng, B. (1991). Cultural relativity in action: A comparison of self-ratings made by Chinese and U.S. workers. Personnel Psychology, 44(1), 129-147.

Farrell, D., \& Petersen, J. C. (1982). Patterns of political behavior in organizations. Academy of Management Review, 7, 403-412.

Fedor, D. B., Bettenhausen, K. L., \& Davis, W. (1999). Peer reviews: Employees' dual roles as raters and recipients. Group and Organization Management, 24(1), 92-120.

Fernandez, D. R., \& Perrewe, P. L. (1995). Implicit stress theory: An experimental examination of subjective performance information on employee evaluations. Journal of Organizational Behavior, 16(4), 353-362.

Foo, S., \& Hui, S. C. (1998). A framework for evaluating Internet telephony systems. Internet Research, 8(1), 14-25.

Fried, Y., Levi, A. S., Ben-David, H. A., \& Tiegs, R. B. (1999). Inflation of subordinates' performance ratings: Main and interactive effects of rater negative affectivity, documentation of work behavior, and appraisal visibility. Journal of Organizational Behavior, 20(4), 431-444.

Gaugler, B. B., \& Rudolph, A. S. (1992). The influence of assessee performance variation on assessors' judgments. Personnel Psychology, 45(1), 77-98.

Gilbert, G. R., Hannan, E. L., \& Lowe, K. B. (1998). Is smoking stigma clouding the objectivity of employee performance appraisal? Public Personnel Management, 27(3), 285-300.

Gioia, D. A., \& Longenecker, C. O. (1994). Delving into the dark side: The politics of executive appraisal. Organizational Dynamics, 22(3), 47-58.

Gittleman, M., Horrigan, M., \& Joyce, M. (1998). "Flexible" workplace practices: Evidence from a nationally representative survey. Industrial and Labor Relations Review, 52(1), 99-115.

Goodson, J. R., McGee, G. W., \& Seers, A. (1992). Giving appropriate performance feedback to managers: An empirical test of content and outcomes. Journal of Business Communication, 29(4), 329-342.

Gunnigle, P., Turner, T., \& D’Art, D. (1998). Counterpoising collectivism: Performance-related pay and industrial relations in Greenfield sites. British Journal of Industrial Relations, 36(4), 565-579.

Halpert, J. A., Wilson, M. L., \& Hickman, J. L. (1993). Pregnancy as a source of bias in performance appraisals. Journal of Organizational Behavior, 14(7), 649-663.

Harris, M. M., Smith, D. E., \& Champagne, D. (1995). A field study of performance appraisal purpose: Research- versus administrative-based ratings. Personnel Psychology, 48(1), 151-160.

Healy, G. (1997). The industrial relations of appraisal: The case of teachers. Industrial Relations Journal, 28(3), 206-220.

Hedge, J. W. \& Teachout, M. S. (2000). Exploring the concept of acceptability as a criterion for evaluating performance measures. Group and Organization Management, 25(1), 2244.

Heery, E. (1997). Performance-related pay and trade union derecognition. Employee Relations, 19(3), 208-221.

Hooijberg, R., \& Choi, J. (2000). Which leadership roles matter to whom? An examination of rater effects on perceptions of effectiveness. Leadership Quarterly, 11(3), 341-364.

Jae-yong, P. (2002, July 18). Risks of performance-based pay: Report warns of individualism at team's expense. JoongAng Ilbo, p. 6.

Janssens, M. (1994). Evaluating international managers' performance: Parent company standards as control mechanism. International Journal of Human Resource Management, 5(4), 853-873.

Jawahar, I. M., \& Williams, C. R. (1997). Where all the children are above average: The performance appraisal purpose effect. Personnel Psychology, 50(4), 905-926.

Johnson, J. W., \& Ferstl, K. L. (1999). The effects of interrater and self-other agreement on performance improvement following upward feedback. Personnel Psychology, 52(2), 271-303.

Kane, J. S. (1996). The conceptualization and representation of total performance effectiveness. Human Resource Management Review, 6(2), 123-145.

Kolb, J. A. (1995). Leader behaviors affecting team performance: Similarities and differences between leader/ members assessments. Journal of Business Communication, 32(3), 233-248.

Korsgaard, M. A. (1996). The impact of self-appraisals on reactions to feedback from others: The role of selfenhancement and self-consistency concerns. Journal of Organizational Behavior, 17(4), 301-311.

Korsgaard, M. A., \& Roberson, L. (1995). Procedural justice in performance evaluation: The role of instrumental and noninstrumental voice in performance appraisal discussions. Journal of Management, 21(4), 657-669.

Kover, A. J., Goldberg, S. M., \& James, W. L. (1995). Creativity vs. effectiveness? An integrating classification for advertising. Journal of Advertising Research, 35(6), 29-40.

Lam, S. S. K., \& Schaubroeck, J. (1999). Total quality management and performance appraisal: An experimental 
study of process versus results and group versus individual approaches. Journal of Organizational Behavior, 20(4), 445 457.

Lance, C. E. (1994). Test of a latent structure of performance ratings derived from Wherry's (1952) theory of rating. Journal of Management, 20(4), 757-771.

Lance, C. E., Woehr, D. J., \& Fisicaro, S. A. (1991). Cognitive categorization processes in performance evaluation: Confirmatory tests of two models. Journal of Organizational Behavior, 12(1), 1-20.

Lee, J. S. Y., \& Akhtar, S. (1996). Determinants of employee willingness to use feedback for performance improvement: Cultural and organizational interpretations. International Journal of Human Resource Management, 7(4), 878-890.

Lee, M., \& Son, B. (1998). The effects of appraisal review content on employees' reactions and performance. International Journal of Human Resource Management, 9(1), 203-214.

Levy, P. E., \& Williams, J. R. (1998). The role of perceived system knowledge in predicting appraisal reactions, job satisfaction, and organizational commitment. Journal of Organizational Behavior, 19(1), 53-65.

London, M., \& Wohlers, A. J. (1991). Agreement between subordinate and self-ratings in upward feedback. Personnel Psychology, 44(2), 375-390.

Long, B. W. (1991). Performance criticism and questions of value. Text and Performance Quarterly, 11(2), 106-115.

Longenecker, C. O., \& Nykodym, N. (1996). Public sector performance appraisal effectiveness: A case study. Public Personnel Management, 25(2), 151-164.

Lowry, P. E. (1991). The assessment center: Reducing interassessor influence. Public Personnel Management, 20(1), 19-26.

Lowry, P. E. (1996). A survey of the assessment center process in the public sector. Public Personnel Management, 25(3), 307-321.

McEvoy, G. M. (1990). Public sector managers' reactions to appraisals by subordinates. Public Personnel Management, 19(2), 201-212.

Miller,C. S., Kaspin, J. A., \& Schuster, M. H. (1990). The impact of performance appraisal methods on age discrimination in employment act cases. Personnel Psychology, 43(3), 555578.

Morrison, E. W. (1995). Information usefulness and acquisition during organizational encounter. Management Communication Quarterly, 9(2), 131-155.

Mount, M. K., Judge, T. A., Scullen, S. E., Sytsma, M. R., \& Hezlett, S. A.. (1998). Trait, rater and level effects in 360-degree performance ratings. Personnel Psychology, 51(3), 557-576.

Mount, M. K., Sytsma, M. R., Hazucha, J. F., \& Holt, K. E. (1997). Rater-ratee race effects in developmental performance ratings of managers. Personnel Psychology, 50(1), 51-69.

Owen, D. (1997). Talk radio and evaluations of President Clinton. Political Communication, 14(3), 333-353.
Paik, Y., Vance, C. M., \& Stage, H. D. (2000). A test of assumed cluster homogeneity for performance appraisal management in four Southeast Asian countries. International Journal of Human Resource Management, 11(4), 736-750.

Pan, Z. \& Kosicki, G. M. (1997). Priming and media impact on the evaluations of the president's performance. Communication Research, 24(1), 3-30.

Park-Fuller, L. M., \& Pelias, R. J. (1995). Charting alternative performance and evaluative practices. Communication Education, 44(2), 126-139.

Peiperl, M.A. (1999). Conditions for the success of peer evaluation. International Journal of Human Resource Management, 10(3), 429-458.

Peterson, S. B. (1998). Saints, demons, wizards, and systems: Why information technology reforms fail or underperform in public bureaucracies in Africa. Public Administration and Development, 18(1), 37-60.

Plax, T. G., Beatty, M. J., \& Feingold, P. C. (1991). Predicting verbal plan complexity from decision rule orientation on business students and corporate executives. Journal of Applied Communication Research, 19(4), 242-262.

Ragins, B. R. (1991). Gender effects in subordinate evaluations of leaders: Real or artifact? Journal of Organizational Behavior, 12(3), 259-268.

Ralston, R. W., \& Waters, R. O. (1996). The impact of behavioral traits on performance appraisal. Public Personnel Management, 25(4), 409-421.

Reilly, R. R., Smither, J. W., \& Vasilopoulos, N. L. (1996). A longitudinal study of upward feedback. Personnel Psychology, 49(3), 599-612.

Roberson, L, Torkel, S., Korsgaard, A., Klein, D., Diddams, M., \& Cayer, M. (1993). Self-appraisal and perceptions of the appraisal discussion: A field experiment. Journal of Organizational Behavior, 14(2), 129-142.

Roberts, G. E. (1994a). Barriers to municipal government performance appraisal systems: Evidence from a survey of municipal personnel administrators. Public Personnel Management, 23(2), 225-236.

Roberts, G. E. (1994b). Maximizing performance appraisal system acceptance: Perspectives from municipal government personnel administrators. Public Personnel Management, 23(4), 525-549.

Roberts, G. E. (1995). Municipal government performance appraisal system practices: Is the whole less than the sum of its parts? Public Personnel Management, 24(2), 197-221.

Roberts, G. E. (1998). Perspectives on enduring and emerging issues in performance appraisal. Public Personnel Management, 27(3), 301-320.

Roberts, G. E., \& Pavlak, T. (1996). Municipal government personnel professionals and performance appraisal: Is there a consensus on the characteristics of an effective appraisal system? Public Personnel Management, 25(3), 379-408.

Robinson, R. K., Fink, R. L., \& Allen, B. M. (1996). The influence of organizational constituent groups on rater attitudes toward performance appraisal compliance. Public Personnel Management, 25(2), 141-150. 
Saks, A. M., \& Waldman, D. A. (1998). The relationship between age and job performance evaluations for entry-level professionals. Journal of Organizational Behavior, 19(4), 409-419.

Salam, S., Cox, J. F., \& Sims, Jr., H. P. (1997). In the eye of the beholder: How leadership relates to 360-degree performance ratings. Group and Organization Management, 22(2), 185209.

Snape, E., Thompson, D., Yan, F. K., \& Redman, T.(1998). Performance appraisal and culture: Practice and attitudes in Hong Kong and Great Britain. International Journal of Human Resource Management, 9(5), 841-861.

Taylor, M.S., Tracy, K. B., Renard, M. K., Harrison, J. K., \& Carroll, S. J. (1995). Due process in performance appraisal: A quasi-experiment in procedural justice. Administrative Science Quarterly, 40(3), 495-523.

Taylor, P. J., \& Pierce, J. L. (1999). Effects of introducing a performance management system on employees' subsequent attitudes and effort. Public Personnel Management, 28(3), 423-452.

Tharenou, P. (1995). The impact of a developmental performance appraisal program on employee perceptions in an Australian federal agency. Group and Organization Management, 20(3), 245-271.

Thorsteinson, T. J., \& Balzer, W. K. (1999). Effects of coworker information on perceptions and ratings of performance. Journal of Organizational Behavior, 20(7), 1157-1173.

Townley, B. (1999). Practical reason and performance appraisal. Journal of Management Studies, 36(3), 287-306.

Tziner, A., Joanis, C., \& Murphy, K. R. (2000). A comparison of three methods of performance appraisal with regard to goal properties, goal perception, and ratee satisfaction. Group and Organization Management, 25(2), 175-190.

Tziner, A., Latham, G. P., Price, B. S., \& Haccoun, R. (1996). Development and validation of a questionnaire for measuring perceived political considerations in performance appraisal. Journal of Organizational Behavior, 17(2), 179-190.

Vardi, Y., \& Weitz, E. (2004). Misbehavior in organizations: Theory, research, and management. Mahwah, NJ: Lawrence Erlbaum Associates.

Varma, A., Denisi, A. S., \& Peters, L. H. (1996). Interpersonal affect and performance appraisal: A field study. Personnel Psychology, 49(2), 341-360.
Waldman, D. A. (1997). Predictors of employee preferences for multirater and group-based performance appraisal. Group and Organization Management, 22(2), 264-287.

Walker, A. G., \& Smither, J. W. (1999). A five-year study of upward feedback: What managers do with their results matters. Personnel Psychology, 52(2), 393-423.

Wanguri, D. M. (1995). A review, an integration, and a critique of cross-disciplinary research on performance appraisals, evaluations, and feedback: 1980-1990. Journal of Business Communication, 32(3), 267-293.

Warech, M. A., Smither, J. W., Reilly, R. R., Millsap, R. E., \& Reilly, S. P. (1998). Self-monitoring and 360-degree ratings. Leadership Quarterly, 9(4), 449-473.

Weekley, J. A., \& Jones, C. (1997). Video-based situational testing. Personnel Psychology, 50(1), 25-49.

Werner, J. M., \& Bolino, M. C. (1997). Explaining U.S. Courts of Appeals decisions involving performance appraisal: Accuracy, fairness, and validation. Personnel Psychology, 50(1), 1-24.

Westerman, J. W., \& Rosse, J. G. (1997). Reducing the threat of rater nonparticipation in 360-degree feedback systems: An exploratory examination of antecedents to participation in upward ratings. Group and Organization Management, 22(2), 288-309.

Whitfield, K. (2000). High-performance workplaces, training, and the distribution of skills. Industrial Relations, 39(1), 1-25.

Wiersma, U. J., van den Berg, P. T., \& Latham, G. P. (1995). Dutch reactions to behavioral observation, behavioral expectation, and trait scales. Group and Organization Management, 20(3), 297-309.

Williams, J. R., \& Levy, P. E. (1992). The effects of perceived system knowledge on the agreement between self-ratings and supervisor ratings. Personnel Psychology, 45(4), 835847.

Williams, S. L., \& Hummert, M. L. (1990). Evaluating performance appraisal instrument dimensions using construct analysis. Journal of Business Communication, 27(2), 117-135.

Woehr, D. J. (1992). Performance dimension accessibility: Implications for rating accuracy. Journal of Organizational Behavior, 13(4), 357-367.

Woehr, D. J., \& Miller, M. J. (1997). Distributional ratings of performance: More evidence for a new rating format. Journal of Management, 23(5), 705-720. 